\title{
Resistance to Flexural Fatigue of Reciproc R25 Files under Continuous Rotation and Reciprocating Movement
}

\author{
Giulio Gavini, DDS, MSc, PbD, * Celso Luiz Caldeira, DDS, MSc, PbD, * \\ Eduardo Akisue, DDS, MSc, PhD, ${ }^{\dagger}$ George Táccio de Miranda Candeiro, DDS, MSc, ${ }^{\neq}$ \\ and Dirce Akemi Sacaguti Kawakami, DDS, MSc ${ }^{\dagger}$
}

\section{Alsstract}

Introduction: The aim of the present work was to evaluate the resistance to flexural fatigue of Reciproc R25 nickel-titanium files, $25 \mathrm{~mm}$, used in continuous rotation motion or reciprocation motion, in dynamic assays device. Methods: Thirty-six Reciproc R25 files were divided into 2 groups ( $n=18$ ) according to kinematics applied, continuous rotary (group (R) and reciprocation motion (group RM). The files were submitted to dynamic assays device moved by an electric engine with $300 \mathrm{rpm}$ of speed that permitted the reproduction of pecking motion. The files run on a ring's groove of temperate steel, simulating instrumentation of a curved root canal with $40^{\circ}$ and $5 \mathrm{~mm}$ of curvature radius. The fracture of file was detected by sensor of device, and the time was marked. The data were analyzed statistically by Student's $t$ test, with level of significance of $95 \%$. Results: The instruments moved by reciprocating movement reached significantly higher numbers of cycles before fracture (mean, 1787.78 cycles) when compared with instruments moved by continuous rotary (mean, 816.39 cycles). Conclusions: The results showed that the reciprocation motion improves flexural fatigue resistance in nickel-titanium instrument Reciproc R25 when compared with continuous rotation movement. (J Endod 2012;38:684-687)

\section{Key Words}

Cyclic fatigue, nickel-titanium, rotary files

From the *Department of Restorative Dentistry, School of Dentistry, Universidade de São Paulo, São Paulo; ${ }^{\dagger}$ School of Dentistry, Universidade Santa Cecília, Santos; and ${ }^{\ddagger}$ Post-Graduate Program in Endodontics, School of Dentistry, Universidade de São Paulo, São Paulo, São Paulo, Brazil.

Address requests for reprints to Prof Dr Giulio Gavini, School of Dentistry, University of Sao Paulo, Department of Restorative Dentistry, Endodontics Division, Av. Prof. Lineu Prestes, 2227, CEP 05508-000, São Paulo, SP, Brasil. E-mail address: ggavini@usp.br

0099-2399/\$ - see front matter

Copyright ( $\odot 2012$ American Association of Endodontists. doi:10.1016/j.joen.2011.12.033
$\mathrm{N}_{\mathrm{c}}^{\mathrm{i}}$ ickel-titanium (NiTi) rotary files are used to achieve the shaping goals during the canal preparation phase, with many advantages over stainless steel files such as high flexibility, cutting efficiency, and fastness (1). Despite the increasing use of NiTi rotary systems worldwide, their cost, possibility of cross-contamination (2), and unexpected separation by fatigue after extended clinical life span are notable disadvantages (3-5). Actually, single use of rotary files has been recommended to reduce instrument fatigue and avoid cross-contamination (1).

Recently, a new concept for root canal preparation was introduced where only 1 F2 ProTaper (Dentsply Tulsa Dental, Tulsa, OK) instrument was used in reciprocation movement (1). In this movement, the instrument rotates in counterclockwise (CCW) and clockwise (CW) directions, with $120^{\circ}$ of difference between both movements. To each 3 cycles, there is a whole rotation of instrument. Thus, the instruments are used at 10 cycles of reciprocation per second, the equivalent of $300 \mathrm{rpm}$ (6). According to the manufacturer, the motor is programmed with the angles of reciprocating. When the instrument rotates in the cutting direction, it will advance in the canal and engage dentin to cut it. When it rotates in the opposite direction (smaller rotation), the instrument will be immediately disengaged. The end result, related to the degree of $\mathrm{CW}$ and CCW rotations, is an advancement of the instrument in the canal. Consequently, only very light apical pressure should be applied on the instrument, because its advancement would be almost automatic. This action reduces the cyclic fatigue (7) and subsequent file fracture $(1,8)$ and requires less working time during root canal preparation phase.

Reciproc R25 (VDW GmbH, Munich Germany) is a \#25.08 taper instrument made of superelastic NiTi M-Wire that presents greater (nearly 300\%-800\%) flexibility and resistance to cyclic fatigue $(5,9,10)$ than conventional NiTi wire $(5)$. The aim of the present study was to evaluate the resistance to flexural fatigue of Reciproc R25 NiTi files, $25 \mathrm{~mm}$, used in continuous rotation or reciprocation motion, in a dynamic testing device. Thus, the null hypothesis proposed is that there is no difference between reciprocating motion and continuous rotation with regard to cyclic fatigue resistance.

\section{Materials and Methods}

Thirty-six Reciproc R25 instruments, $25 \mathrm{~mm}$, were divided into 2 groups with 18 instruments according to kinematics applied: continuous rotation (group CR) and reciprocating movement (group $\mathrm{RM}$ ).

Cyclic fatigue testing was performed with a custom-made apparatus specifically designed to allow dynamic testing by simulating the pecking motion (Fig. 1). An electric motor handpiece VDW Silver Reciproc (VDW GmbH) was used with a contra-angle of 20:1. First, the micromotor/contra-angle handpiece was secured to the support arm in a parallel position to the apparatus base. Then, the Reciproc R25 file was secured to the contra-angle handpiece, ensuring correct locking. At this moment, the electric motor was standardized to perform continuous rotation (group CR) at a rate of $300 \mathrm{rpm}$ and reciprocating movement (group RM), characterized by rotation in CCW and in $\mathrm{CW}$, with $120^{\circ}$ of difference between both movements, performing 10 cycles of reciprocation per second, the equivalent of $300 \mathrm{rpm}$.

The platforms were moved by using the grading rings until reaching a position that allowed the file to remain curved and free to rotate between the cylinder and the steel jig, 


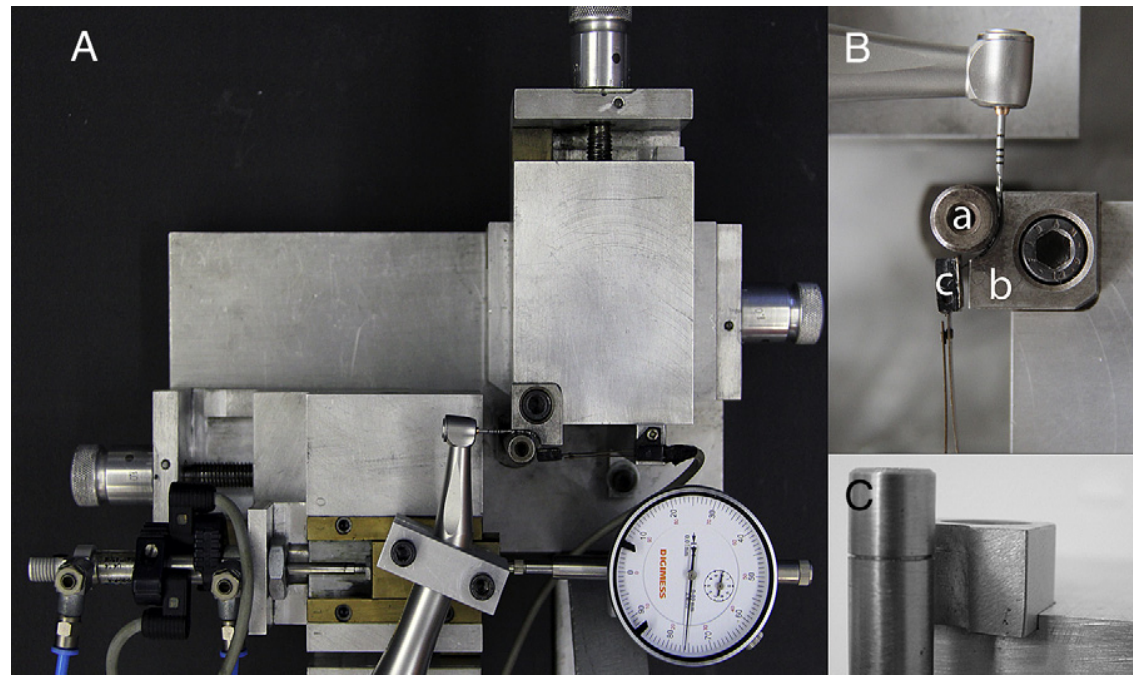

Figure 1. (A) Cyclic fatigue testing apparatus (upper view). (B) Upper view of the hardened steel jig in relation to the cylinder: (a) 10-cm long, 5-mm radius cylinder, secured to the base, containing a 1-mm deep groove located $3.5 \mathrm{~cm}$ from the upper end, designed to hold the file; (b) hardened steel jig, secured to the right upper platform, containing a concave surface on the internal corner compatible with cylinder diameter (jig and cylinder allow the instrument to remain at the same time curved and free to rotate); (c) micro switch (sensor) located at the groove of the banded steel cylinder/block, which electronically detects each touch of the tip of the file (registering the exact moment of breakage of the file). The sensor is protected by a steel plate to avoid wear. $(C)$ Side view of the cylinder and groove.

thus simulating rotary instrumentation of a canal with a $40^{\circ}, 5-\mathrm{mm}$ radius curvature. Care was taken to ensure that the instrument was well positioned in the cylinder groove to avoid file displacement. The instrument tip remained visible throughout the experiment, touching a snap-action switch sensor (SMEO-4U-K-LED-24; Festo, São Paulo, Brazil) when the maximum displacement of the pneumatic system was achieved.

With the file properly positioned, the main switch was turned on, the electric motor was powered, and simultaneously turned on the pneumatic switch. With that, the whole set of micromotor/contraangle/file was powered by the pneumatic system, reproducing the pecking motion, with $2 \mathrm{~mm}$ in each (forward or backward) direction, during which the file slid in the groove in the ring made of tempered steel. This movement took place at a speed of 1 cycle per second. The fracture of the instrument was easily detected by the snap-action switch sensor at the moment the counter and timer were stopped. Testing time was automatically registered with a digital stopwatch (Casio Corp, Tokyo, Japan), which was started at the moment the motor was turned on and stopped at fracture detection. After completion of all tests, the mean time to failure observed in each group was recorded in seconds and subsequently converted to number of cycles to fracture.

The fractured surfaces of 5 files from each group were examined under a LEO 435 VP scanning electron microscope (LEO 435 VP; CarlZeiss NTS GmbH, Oberkochen, Germany) to characterize qualitatively the fracture pattern at magnifications of $350 \times, 1000 \times, 2500 \times$, and $10,000 \times$ for secondary electron detection mode (SE) and $1200 \times$ for backscattered electron detection mode (QBSD).

Because our study included 2 independent sets of samples with normal distribution and equal variances, Student's $t$ test was used to assess the presence of statistically significant differences between groups $(P<.05)$.

\section{Results}

The mean and standard deviation values of the fatigue resistance data were computed. A statistically significant difference was observed for cyclic fatigue resistance of the Reciproc R25 between continuous rotary and reciprocation movements. Table 1 shows the results for the number of cycles to failure for each group and for Student's $t$ test. Instruments operated in reciprocation motion showed significantly higher number of cycles to fracture when compared with instruments in continuous rotation.

Figure $2 A-C, E-H$ shows scanning electron microscopy (SEM) micrographs of the surface morphology of Reciproc R25 file fractured after continuous rotation and reciprocating movement, respectively. The SEM images showed fatigue striations that characterize the occurrence of fatigue failure and result in spherical dimples that are representative of a ductile fracture. Micro-voids and cracks were also found. The backscattered electron detection mode (QBSD) enhances the characterization of striations in Figure $2 B 1$.

\section{Discussion}

In the present research, the null hypothesis was rejected because the results showed that the kinematics of movements of NiTi rotary instruments influences significantly the cyclic fatigue of Reciproc R25 files. The number of cycles $(1787.78 \pm 369.94)$ to fracture was nearly twice as much for instruments under reciprocation motion compared with the same instruments under continuous rotation $(816.39 \pm$ 106.84)

Despite greater flexibility and torsion resistance, separation is the main problem in endodontic NiTi files, especially during extended clinical uses $(11,12)$, resulting in a ductile fracture type. Cyclic fatigue happens when the instrument is rotating inside curved canals at their

TABLE 1. Mean Cycles to Failure, Standard Deviation, and Student's $t$ Test

\begin{tabular}{|c|c|c|c|c|c|c|c|}
\hline Groups & Movement & Tip size/taper & $\mathbf{n}$ & Time to failure (seconds) & Mean cycles to fracture & Standard deviation & $P$ value \\
\hline $\begin{array}{l}\text { CR } \\
\text { RM }\end{array}$ & $\begin{array}{l}\text { Continuous } \\
\text { Reciprocating }\end{array}$ & $\begin{array}{l}25 / 08 \\
25 / 08\end{array}$ & $\begin{array}{l}18 \\
18\end{array}$ & $\begin{array}{l}163.28 \\
357.56\end{array}$ & $\begin{array}{r}816.39 \\
1787.78\end{array}$ & $\begin{array}{l}106.84 \\
369.94\end{array}$ & $<.0001$ \\
\hline
\end{tabular}




\section{Basic Research-Technology}

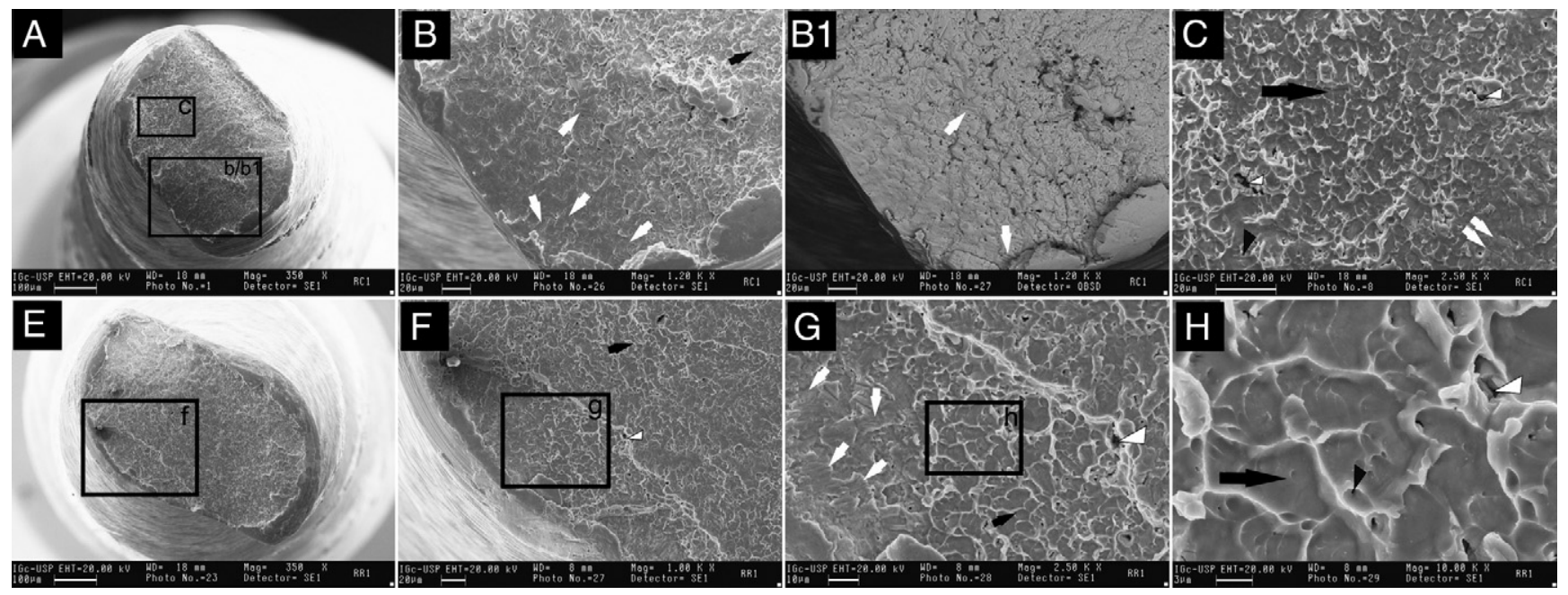

Figure 2. ( $A$ and $E$ ) Fracture surfaces in instruments broken used with continuous rotation and reciprocating movement, respectively, exhibiting plastic deformation (original magnification, $350 \times$ ). ( $B$ and $B 1$ ) Higher magnification view (original magnification, $1200 \times$ ) of areas b and b1 $(A, b o x)$ showing dimples (black arrow) and fatigue striations (white arrow). (B1) SEM backscattered electron detection mode showing striations that indicate the occurrence of fatigue failure. $(C)$ Higher magnification view (original magnification, $2500 \times)$ of area c $(A, b o x)$ exhibiting micro-voids (black arrowhead), dimples, fatigue striations, and cracks (white arrowhead). $(F)$ Higher magnification view (original magnification, $1000 \times)$ of area $\mathrm{f}(E$, box $)$ showing dimples and cracks. $(G)$ Higher magnification view of area $\mathrm{g}(F, b o x)$ presenting crack, dimples, and fatigue striations (original magnification, $2500 \times)$. (H) Higher magnification view of area $\mathrm{h}(G, b o x)$ exhibiting cracks, spherical dimples, and micro-voids (original magnification, 10,000×).

maximal flexure where continuous traction and compression cycles, which add to the torsional stress, all contributed to the instrument fracture (13-19). Therefore, most cases of mechanical failure of NiTi rotary files during clinical use have been associated with flexural fatigue $(11,20)$

In clinical situations, both torsional stress and cyclic fatigue are exerted on the files within the curved root canal, and these 2 forces influence each other. Therefore, NiTi files exposed to torsional stress are prone to fracture at a lower number of load cycles (21). Many factors can affect the cyclic fatigue behavior of NiTi instruments, such as radius $(9,15,22)$ and angle of curvature of the root canal, number of uses of the files, motor torque, dentist's experience $(23,24)$, the NiTi system used, file surface treatment (25), motor speed, and sterilization method (26).

In ductile fractures micro-voids are produced within the metal, and nucleation, growth, and micro-void coalescence ultimately weaken the metal and result in fracture $(26,27)$. Plastic deformation because of slip, the process by which a dislocation moves in response to shear stresses, also contributes to ductile fracture (28). In the present research, SEM images of all files showed fracture surface of rotary NiTi instrument with the characteristic striations and dimpling resulting from flexural (cyclic) fatigue, according to some previous studies $(4,7,12)$.

In reciprocating movement proposed by Yared (1), the instrument engages in the canal when rotating in CCW direction and disengages in $\mathrm{CW}$ direction. Because the $\mathrm{CCW}$ rotation is greater than the $\mathrm{CW}$ rotation, the end result is a screwing-in effect (1), with reduction of compressive forces favoring the occurrence of elastic deformation, decrease of flexural fatigue $(7)$ and of torsional fracture by taper lock $(1,8)$. This fact was confirmed by results of the present study, when analyzing the same parameter, demonstrated that when using the reciprocating movement of Reciproc NiTi files, the average time until fracture was twice as long (357.56 seconds) as the same file under continuous movement (163.28 seconds).

These data are still according to previous studies on the effect of reciprocating movement on cyclic fatigue life of the F2 ProTaper instru- ment $(7,8)$. De-Deus et al $(7)$ showed that movement kinematics is a determining factor on cyclic fatigue of rotary NiTi instruments where the reciprocating movement (95 seconds to fracture) is superior to conventional rotation (25 seconds).

According to previous studies that showed fractured NiTi surfaces by using SEM analysis $(4,7,12,29)$, in the present study, SEM images showed micro-void crater-like and spherical dimples, which are representative of a ductile fracture resulting from the catastrophic failure of the material once the fatigue crack has attained a certain critical depth (Fig. 2).

In conclusion, the use of the Reciproc R25 file under reciprocating movement showed a higher mechanical resistance to flexural fatigue than when used in continuous rotation movement.

\section{Acknowledgments}

The authors deny any conflicts of interest related to this study.

\section{References}

1. Yared G. Canal preparation using only one Ni-Ti rotary instrument: preliminary observations. Int Endod J 2008;41:339-44.

2. Sonntag D, Peters OA. Effect of prion decontamination protocols on nickel-titanium rotary surfaces. J Endod 2007;33:442-6.

3. Alapati SB, Brantley WA, Svec TA, Powers JM, Mitchell JC. Scanning microscope observations of new and used nickel-titanium rotary files. J Endod 2003;29: 667-9.

4. You SY, Bae KS, Baek SH, Kum KY, Shon WJ, Lee W. Lifespan of one nickel-titanium rotary file with reciprocating motion in curved root canals. J Endod 2010;36: 1991-4.

5. Shen Y, Qian W, Abtin H, Gao Y, Haapasalo M. Fatigue testing of controlled memory wire nickel-titanium rotary instruments. J Endod 2011;37:997-1001.

6. Yared G. Canal preparation with only one reciprocating instrument without prior hand filing: a new concept. Available at: http:/www.vdw-reciproc.de/images/ stories/pdf/GY_Artikel_en_WEB.pdf. Accessed December 9, 2011.

7. De-Deus G, Moreira EJL, Lopes HP, Elias CN. Extended cyclic fatigue life of F2 ProTaper instrument used in reciprocating movement. Int Endod J 2010;43:1063-8.

8. Varela-Patino P, Ibanez-Parraga A, Rivas-Mundina B, Cantatore G, Otero XL, MartinBiedma B. Alternating versus continuous rotation: a comparative study of the effect on instrument life. J Endod 2010;36:157-9. 
9. Johnson E, Lloyd A, Kuttler S, Namerow K. Comparison between a novel nickeltitanium alloy and 508 nitinol on the cyclic fatigue life of ProFile 25/.04 rotary instruments. J Endod 2008;34:1406-9.

10. Gao Y, Shotton V, Wilkinson K, Phillips G, Johnson WB. Effects of raw material and rotational speed on the cyclic fatigue of ProFile Vortex rotary instruments. J Endod 2010;36:1205-9.

11. Wu J, Lei G, Yan M, Yu Y, Yu J, Zhang G. Instrument separation analysis of multi-used ProTaper Universal rotary system during root canal therapy. J Endod 2011;37: 758-63.

12. Parrashos P, Messer HH. Rotary NiTi instrument fracture and its consequences. J Endod 2006;32:1031-43.

13. Pruett JP, Clement DJ, Carnes DL Jr. Cyclic fatigue testing of nickel-titanium endodontic instruments. J Endod 1997;23:77-85.

14. Haikel Y, Serfaty R, Bateman G, Senger B, Allemann C. Dynamic and cyclic fatigue of engine-driven rotary nickel-titanium endodontic instruments. J Endod 1999;25: 434-40.

15. Yared GM, Bou Dagher FE, Machtou P. Cyclic fatigue of ProFile rotary instruments after clinical use. Int Endod J 2000;33:204-7.

16. Li UM, Lee BS, Shih CT, Lan WH, Lin CP. Cyclic fatigue of endodontic nickel-titanium rotary instruments: static and dynamic tests. J Endod 2002;28:448-51.

17. Yao JH, Schwartz SA, Beeson TJ. Cyclic fatigue of three types of rotary nickel-titanium files in a dynamic model. J Endod 2006;32:55-7.

18. Ray JJ, Kirkpatrick TC, Rutledge RE. Cyclic fatigue of EndoSequence and K3 rotary files in a dynamic model. J Endod 2007;33:1469-72.

19. Gambarini G, Grande NM, Plotino G, et al. Fatigue resistance of engine-driven rotary nickel titanium instruments produced by new manufacturing methods. J Endod 2008;34:1003-5.
20. Spanaki-Voreadi AP, Kerezoudis NP, Zinelis S. Failure mechanism of ProTaper Ni-Ti rotary instruments during clinical use: fractographic analysis. Int Endod J 2006;39: 171-8.

21. Galvão Barbosa FO, Ponciano Gomes JA, Pimenta de Araújo MC. Influence of previous angular deformation on flexural fatigue resistance of $\mathrm{K} 3$ nickel-titanium rotary instruments. J Endod 2007;33:1477-80.

22. Zelada G, Varela P, Martín B, Bahillo JG, Magán F, Ahn S. The effect of rotational speed and the curvature of root canals on the breakage of rotary endodontic instruments. J Endod 2002;28:540-2.

23. Yared GM, Bou Dagher FE, Machtou P. Influence of rotational speed, torque and operator's proficiency on ProFile failures. Int Endod J 2001;34: 47-53.

24. Mesgouez C, Rilliard F, Matossian L, Nassiri K, Mandel E. Influence of operator experience on canal preparation time when using the rotary Ni-Ti ProFile system in simulated curved canals. Int Endod J 2003;36:161-5.

25. Gavini G, Pessoa OF, Barletta FB, Vasconcellos MAZ, Caldeira CL. Cyclic fatigue resistance of rotary nickel-titanium instruments submitted to nitrogen ion implantation. J Endod 2010;36:1183-6.

26. Melo MCC, Bahia MGA, Buono VTL. Fatigue resistance of engine-driven rotary nickel-titanium endodontic instruments. J Endod 2002;28:765-9.

27. Christ HJ. Fundamental mechanisms of fatigue and fracture. Stud Health Technol Inform 2008;133:56-67.

28. Askeland D, Phule P. The science of engineering of materials. 4th ed. Pacific Grove, CA: Brooks/Cole-Thompson Learning; 2003.

29. Vaidyanathan R, Dunand DC, Ramamurty U. Fatigue crack-growth in shape-memory NiTi and NiTi-TiC composites. Mater Sci Eng A 2000; 289:208-16. 